infants in hospital might receive unnecessary intravenous antibiotics if thought to have pneumonia. Does early diagnosis make any difference to the outcome? Individual medical practitioners variously recommend erythromycin or co-trimoxazole, salbutamol, steroids, antitussives, sedatives, and atropine methonitrate. Reviewing published reports on treatment, Broomhall and Herxheimer concluded there was no firm evidence for the value of these. ${ }^{7}$

Many doctors believe that early diagnosis is worth while on the grounds that treatment with antibiotics, which needs to be for at least 14 days, reduces infectivity and therefore limits spread. This may be useful when patients are admitted to a hospital ward, but at home old fashioned quarantine is likely to be as effective. Unfortunately, treating asymptomatic close contacts has not been proved protective. ${ }^{8}$ Perhaps the most important reason for trying to make a correct diagnosis in the child at home is the relief of parental anxiety inevitable when there is uncertainty.
The only way to prevent this extremely unpleasant disease is to encourage a high uptake of vaccine.

HARVEY MARCOVITCH

Consultant Paediatrician

Oxfordshire Health Authority,

Oxford OX3 9DZ

1 Sotomayer J, Weiner LB, McMillan JA. Inaccurate diagnosis in infants with pertussis. An eightyear experience. Am $\mathcal{F}$ Dis Child 1985;139:724-7.

year experience. Am $\mathcal{F}$ Dis Child 1985;139:724-7.
Maclean DW. Adults with pertussis. I $R$ Coll Gen Pract 1982;238:298-300.

2 Maclean DW. Adults with pertussis. I R Coll Gen Pract 1982;238:298-300. vaccination uptake on a large community. Br Med J 1981;282:23-6.

4 Robinson DA, Mandal BK, Ironside AG, Dunbar EM. Whooping cough-a study of severity in hospital cases. Arch Dis Child 1981;56:687-91.

5 Gilligan PH, Fisher MC. Importance of culture in laboratory diagnosis of B pertussis infections. $\mathcal{J}$ Clin Microbiol 1984;20:891-3.

6 Boreland PC, Gillespie SH. Countercurrent immunoelectrophoresis in the diagnosis of whooping cough. J Clin Pathol 1984;37:950-5.

Broomhall J, Herxheimer A. Treatment of whooping cough: the facts. Arch Dis Child 1984;59: $185-7$.

8 Grob PR, Spencely M, Lambert HP. Whooping cough in infants: antimicrobial prophylaxis? Lancet 1981;i:772-3.

\title{
Ventricular assist devices
}

The use of mechanical assist devices to support the failing heart is not new. The first clinical attempts with a "left heart assist" were in 1963 and since then devices of this kind have been implanted in around 100 patients-but the concepts, the materials, and even the indications have changed.

In contrast with the total artificial heart, ventricular assist devices are used in parallel with the patient's own heart. Usually one is inserted in a patient with univentricular failure and two in a patient with biventricular failure. The basic elements are a blood sac, inlet and outlet valves, and a drive mechanism. Typically the blood sac has a capacity of 50-70 $\mathrm{ml}$ and is made of flexible, smooth, seam free polyurethane. The valves used to maintain unidirectional flow range from standard mechanical valves of the tilting disc variety to pericardial, porcine, and even dural types. The power source may be either electrical or pneumatic, though research is still being conducted into nuclear and other energy sources. Since most devices are intended to be temporary the conduits can be led through the chest wall; some ventricular assist devices are implantable with only electrical leads leaving the body. The ideal solution in these cases would be an implantable power source that could be recharged through the intact skin; research in animals is well advanced.

At present there are three main indications for the use of assist devices. Firstly, some patients cannot be weaned from cardiopulmonary bypass despite maximal conventional support, including the intra-aortic balloon pump. Secondly, the condition of some patients accepted by a transplant programme may be deteriorating rapidly with no donor heart immediately available. The final group-at the moment less clearly defined-consists of patients in cardiogenic shock after a myocardial infarction, who might require either temporary or permanent support.

What sort of results have been reported? Two of the surgeons with the largest experience around the world are W S Pierce at Pennsylvania and D G Pennington at St Louis. Pierce and colleagues have reported 17 patients who could not be weaned from cardiopulmonary bypass; eight of these eventually recovered their ventricular function and were discharged from hospital. ${ }^{2}$ Pennington reported 21 patients, 10 of whom were weaned from the ventricular assist device with seven being discharged from hospital. ${ }^{3}$

The fear that use of ventricular assist devices would distort existing transplant programmes does not appear to be justified by experience. This has shown the potential of the left ventricle to recover after a period of support. ${ }^{4}$ Ventriculograms in survivors have shown that about half had either normal or mildly depressed ventricular function, though their hearts had been practically lifeless on the operating table. ${ }^{3}$ Furthermore, such patients do not become cardiac cripples: of the 14 in that series eight were employed, five were retired but active, and only one remained disabled.

How many patients might be suitable for support from a ventricular assist device? Nearly $7 \%$ of patients treated by open heart surgery cannot be weaned from cardiopulmonary bypass. ${ }^{56}$ Most, however, respond to volume loading, support with inotropic drugs, and intra-aortic balloon pump counterpulsation. This leaves about $1 \%$ of patients with persisting ventricular inadequacy who require further circulatory support. When the facilities for using ventricular assist devices are not available long term circulatory support is given to patients of this kind by the roller pump method or extracorporeal membrane oxygenation. ${ }^{7.9}$ The longer that the patient remains with the bypass, however, the more damage is caused to the blood elements and in time to the vital organs. Ventricular assist devices may allow the support of these patients with fewer complications.

The technical aspects of the use of ventricular assist devices are still under investigation. For example, Sethia et al have shown that it is preferable to use the left atrium rather than the left ventricle as a source of blood, ${ }^{10}$ and Pennington and colleagues argue that patients with biventricular failure do well only with biventricular suppor $t^{11}$ - but these problems will be resolved in time. The ethical implications are also stimulating debate. Though no mechanical device has the emotional impact of a heart transplant, potential recipients face similar stresses. A main consideration is that the 
outcome is usually clear: either patients die with the pump or they can be weaned from it; only a minority will need permanent assistance or a transplant. Availability of these expensive machines and the training necessary to use them, however, will preclude their widespread use for some time to come. Nevertheless, with ventricular assist devices now in use in Britain we have to consider their costs, benefits, and dangers.

Research Fellow,

BRIAN GLENVILLE

Cardiothoracic Institute,

London W1N 2DX

DONALD Ross

Consultant Cardiac Surgeon,

National Heart Hospital,

London W1M 8BA

Correspondence to: Mr Glenville.
1 Liotta D, Hall CW, Walter SH, Cooley DA, Crawford ES, DeBakey ME. Prolonged assisted circulation during and after cardiac or aortic surgery. Prolonged partial ventricular bypass by circulation during and after cardiac or aortic surgery. Prolonged parti

2 Olsen EK, Pierce WS, Donachy JH, et al. A two and one-half year clinical experience with a mechanical left ventricular assist pump in the treatment of profound postoperative heart failure. In I Artif Organs 1979;2:197-206.

3 Pennington DG. Unilateral and bilateral bypass. In: Glenville BE, Ross DN, eds. Proceedings of update in circulatory support and artificial heart. Third international symposium on cardiac bioprostheses. (In press.)

4 Norman JC, Fuqua JM, Bennett JG, et al. An intracorporeal (abdominal) left ventricular assist device: initial clinical trials. Arch Surg 1977;112:1442-51.

5 Myers JL, Parr GVS, Pae WE, Waldhausen JA, Pierce WS. The role of the ventricular assist pump for postcardiotomy cardiogenic shock: a four and one-half year experience. Proceedings of the 3rd meeting of the ISAO. Artif Organs 1981;suppl 5:244-51.

6 Koffsky RM, Litwak RS, Mitchel BL, Jurado RA. A simple left heart assist for use after intracardiac surgery: development, deployment and clinical experience. Artif Organs 1978;2:257-62.

7 Litwak RS, Koffsky RM, Jurado RA, et al. Use of a left heart assist device after intracardiac surgery: technique and clinical experience. Ann Thorac Surg 1976;21:191-206.

8 Rose DM, Colvin SB, Culliford AT, et al. Long term survival with partial left heart bypass following perioperative myocardial infarction and shock. $\mathcal{J}$ Thorac Cardiovasc Surg 1982;83:483-92.

9 Pennington DG, Merjavy JP, Codd JE, Swartz MT, Miller LL, Williams GA. Extracorporeal membrane oxygenation for patients with cardiogenic shock. Circulation 1984;70:130-7.

10 Sethia B, Martin W, Wheatley DJ. The effects of left atrial and left ventricular cannulation on left ventricular function. Int $\mathcal{J}$ Artif Organs 1985;8:331-4.

11 Pennington DG, Meriavy JP, Swartz MT, et al. The importance of biventricular failure in patients with postoperative cardiogenic shock. Ann Thorac Surg 1985;39:16-26.

\section{A boost for clinical research}

Neither governments nor official bodies are much good at admitting mistakes, so there is a welcome honesty in the Medical Research Council's having acknowledged that its Clinical Research Centre linked with Northwick Park Hospital has not lived up to expectations. A special committee of the MRC was set up a year ago to consider the original concepts and "propose for the future new objectives and organisational changes to support them"; and while the committee has been careful in its report ( $p$ 416) to avoid making any detailed assessment of the quality of the scientific work of the CRC the clear implication of the findings is that something went wrong from very early on.

Possibly the mistake was the planners' belief that by linking the CRC with an ordinary district hospital its research would be mainly concerned with common diseases. The reality was that the hospital's lack of any academic function must have been an important factor in the disappointing outcome. In practice the research staff and the clinicians functioned as two communities-and the MRC committee found evidence of "growing divergence" between them. Possibly this may have been linked with the growing numbers of the NHS consultant staff who were devoting an increasing amount of their time to private practice. In the committee's words: "serious clinical research is only exceptionally compatible with any significant commitment to private practice."

The detailed postmortem analysis can (and no doubt will) proceed at leisure. The emphasis now must be on plans for the future-and these need to be straightforward and immediate if the staff concerned are to avoid the sinister effects of "blight and flight." The MRC believes the solution is for the CRC to merge with another unit of proved academic excellence-the Royal Postgraduate Medical School. The fusion would provide the new joint centre with many factors missing from the twinning at Northwick Park-most obviously the university base and teaching programme, the critical mass of top flight academic staff, flexibility in research funding, and specialisation in the main branches of hospital clinical practice. The MRC also argues that future clinical research workers will need to have had training in research in the basic sciences, and it favours eventually bringing its National Institute for Medical Research on to the same site as the Clinical Research Centre.

The committee's clear and decisive report leaves only one main question open-should the CRC move to Hammersmith or the Royal Postgraduate Medical School move to Northwick Park? We prefer the Hammersmith site-if only on the grounds that it has suffered planning blight for so long that it deserves a better deal this time. We hope that the government and the University Grants Committee will recognise that if Britain is to have only one centre of excellence for clinical research that centre should be properly funded-both capital and revenue. And we hope that the University of London and the MRC will have learnt one lesson from the past 20 years of hesitancy and uncertainty about medical mergers. The decision on site should be taken soon and be final-we cannot afford a decade of argument, postponement, and demoralisation. 